\title{
DISAIN DAN PENGUJIAN SISTEM KENDALI SUHU ASAP KAYU KARET UNTUK MENINGKATKAN EFEKTIVITAS PEMBUATAN KARET SIT ASAP BERBASIS MIKROKONTROLLER
}

\author{
Design and Test of Temperature of Rubber Wood Smoke Control System Based on \\ Microcontroller to Improve Effectivity of Ribbed Smoked Sheet Production \\ Suhermanto Agung WIBOWO ${ }^{1 *}$, I Dewa Made SUBRATA ${ }^{2}$, \\ Anjar SUPRAPTO ${ }^{3}$, dan LISYANTO ${ }^{4}$ \\ ${ }^{1}$ Balai Penelitian Sungei Putih, Pusat Penelitian Karet \\ Sungei Putih, Deli Serdang, Sumatera Utara \\ PO Box 1415 Medan 20001 \\ *Email: agung_saw@yahoo.com \\ ${ }^{2}$ Fakultas Teknologi Pertanian, Institut Pertanian Bogor \\ Kampus IPB Dramaga, Jl. Lingkar Akademik Dramaga Bogor 16680 Jawa Barat \\ ${ }^{3}$ Balai Besar Pengembangan Mekanisasi Pertanian \\ J1. Alsintan Sampora Cisauk Tangerang 15338 Banten \\ ${ }^{4}$ Fakultas Teknik, Universitas Negeri Medan \\ J1. Willem Iskandar/Pasar V Medan Sumatera Utara
}

Diterima : 12 Februari 2018 / Disetujui : 19 Februari 2018

\begin{abstract}
Smoking of Ribbed Smoked Sheets (RSS) is a method of rubber sheets preserving and drying using wood smoke to prevent fungus from growing during storage. Generally, conventional RSS smoked takes 56 days and consumes $4 \mathrm{~m}^{3}$ of smoke wood per ton of dry rubber. RSS quality is also determined by routine control of wood fuel and temperature of the smoking room. This research objectivetried to improve RSS quality and energy efficiency on rubber smoked process by implementing automatic micro controller system that could control smoke concentration and temperature. Control system was system that could control temeperature and smoke concentration at each temperature level. The objective of the experiment was to design and test of microcontroller in controlling temeperature and smoke concentration. The experimental procedure included : 1) Design and
\end{abstract}

construction, 2) To design controller hardware, 3) To design software, LM 35 and 5 sensor calibration and 5) Testing of the control system in smoking room. The result of testing of temperature control system and smoke concentration is the process of RSS is divided into 4 levels of temperature ie at $40^{\circ} \mathrm{C}-45^{\circ} \mathrm{C}$ for 12 hours, $45^{\circ} \mathrm{C}-50^{\circ} \mathrm{C}$ for 12 hours, $50^{\circ} \mathrm{C}-55^{\circ} \mathrm{C}$ for 12 hours, and $55^{\circ} \mathrm{C}-60^{\circ} \mathrm{C}$ for 24 hour. The success of this test was achieved at 60 hours or 2.5 days. The RSS quality was transparent brown, no bubble and the sheet was not expand and broken. The RSS became majority as RSS 1 after water evaporation as much as $35.78 \%$. While the length and width $s$ of RSS was shortened as much as $3.81 \%$, $8.95 \%$ respectively, and the thickness increased by $4.36 \%$ The use of wood fuel for smoking was around $1,18 \mathrm{~m}^{3}$ with RSS capacity of $1000 \mathrm{Kg}$.

Keywords: Control system; microcontroller; ribbed smoked sheet; smoked 


\begin{abstract}
Abstrak
Pengasapan karet RSS adalah metode pengawetan dan pengeringan karet lembaran menggunakan asap kayu bakar agar jamur tidak tumbuh saat penyimpanan. Pada umumnya pengasapan karet RSS konvensional membutuhkan waktu 5-6 hari dan konsumsi kayu asap sebanyak $4 \mathrm{~m}^{3}$ per ton karet kering. Selain itu mutu RSS juga ditentukan oleh pengontrolan yang rutin mengenai bahan bakar kayu dan suhu ruang pengasapan. Penelitian ini berupaya meningkatkan mutu karet RSS dan efisiensi energi proses pengasapan karet RSS dengan menerapkan sistem kendali otomatis berbasis mikrokontroller yang dapat mengatur suhu asap kayu karet. Sistem kendali ini merupakan sistem yang akan mengatur suhu dan kepekatan asap pada setiap tingkatan suhu. Tujuan penelitian ini adalah untuk melakukan perancangan dan pengujian pengendalian suhu asap kayu karet dan tingkat kecerahan RSS menggunakan mikrokontroller. Prosedur penelitian ini mencakup; 1) Disain dan Konstruksi, 2) Merancang perangkat keras kendali, 3) Merancang perangkat lunak, 4) Kalibrasi Sensor LM 35 dan 5) Pengujian sistem kendali pada ruang pengasap. Hasil pengujian sistem kendali suhu asap kayu karet adalah proses pengasapan karet RSS terbagi pada 4 tingkatan suhu yaitu suhu $40^{\circ} \mathrm{C}-45^{\circ} \mathrm{C}$ selama 12 jam, suhu $45^{\circ} \mathrm{C}-50^{\circ} \mathrm{C}$ selama $12 \mathrm{jam}$, suhu $50^{\circ} \mathrm{C}-55^{\circ} \mathrm{C}$ selama 12 jam, dan suhu $55^{\circ} \mathrm{C}-60^{\circ} \mathrm{C}$ selama 24 jam. Keberhasilan pengujian ini dicapai selama 60 jam atau 2,5 hari. Mutu karet RSS berwarna coklat transparan, tidak timbul gelembung dan lembaran tidak tambah panjang atau putus. Karet RSS menjadi dominan mutu RSS 1 setelah terjadi penguapan air sebesar 35,78\%. Adapun panjang karet RSS berkurang sebesar $3,81 \%$, lebar berkurang sebesar $8,95 \%$ dan ketebalan bertambah sebesar 4,36\%. Penggunaan kayu bahan bakar asap sekitar $1,18 \mathrm{~m}^{3}$ dengan kapasitas karet RSS 1.000 Kg.
\end{abstract}

Kata kunci : Karet RSS; mikrokontroller; pengasapan; sistem kendali

\section{PENDAHULUAN}

Beberapa wilayah di Indonesia memiliki keadaan lahan yang cocok untuk penanaman karet, sebagian besar berada di wilayah Sumatera dan Kalimantan (Hendratno, 2015). Pengusahaan perkebunan karet di Indonesia dilakukan oleh perkebunan karet rakyat, perkebunan besar negara (PBN), dan perkebunan besar swasta (PBS) (Munafidza, Supardi, \& Nurjayanti, 2015). Luas area perkebunan karet tahun 2015 tercatat mencapai lebih dari 3,62 juta Ha yang tersebar di seluruh wilayah Indonesia. Di antaranya 85\% merupakan perkebunan karet milik rakyat, dan hanya $7 \%$ perkebunan besar negara serta $8 \%$ perkebunan besar milik swasta. Produksi karet secara nasional pada tahun 2015 mencapai 3,14 juta ton (Direktorat Jenderal Perkebunan [Ditjenbun], 2016). Diantara negara-negara produsen karet alam lainnya, Indonesia memiliki luasan areal perkebunan karet terbesar namun dari segi produksi menempati posisi kedua setelah Thailand. Rata-rata produksi karet antara periode 2009-2013, Thailand mencapai 3,39 juta ton, Indonesia 2,85 juta ton, Malaysia 908 ribu ton, India 858 ribu ton, dan Vietnam sebesar 815 ribu ton (Kementerian Pertanian, 2015). Perkebunan besar negara dalam manajemen PT. Perkebunan Nusantara (PTPN) yang secara keseluruhan berjumlah 14 perusahaan namun hanya 11 perusahaan yang mengusahakan komoditas karet. Luas total lahan kebun karet milik perkebunan besar negara mencapai 230.168 Ha dengan produksi sebesar 225.999 ton pada tahun 2015 (Ditjenbun, 2016).

Karet alam adalah senyawa hidrokarbon yang merupakan polimer dari rantai poliisoprena dengan konfigurasi 1,4 cis poliisoprena (Cifriadi, Chalid, \& Puspitasari, 2017). Kemajuan industri karet alam maupun karet sintetis mengalami perkembangan yang pesat terutama barang jadi karet. Bahan olah lateks kebun sebagai bahan mentah yang diolah menjadi bahan setengah jadi dan bahan jadi yang harus disesuaikan dengan persyaratan dalam perdagangan. Lateks kebun yang dipanen dengan mutu baik maka akan menghasilkan bahan olah karet (bokar) yang berkualitas unggul. Hal yang dilakukan agar diperoleh hasil karet yang bermutu tinggi maka kebersihan dalam bekerja merupakan syarat paling utama yang harus diperhatikan seperti kebersihan peralatan sadap dan kemungkinan kontaminasi kotoran (Ginting, Siregar, \& Ginting, 2015). Getah karet yang diperdagangkan terdiri dari bentuk getah 
cair (lateks kebun), bongkahan (slab), lembaran (sheet) dan getah mangkuk (lump) (Hendratno, 2015). Karet mentah alam berdasarkan jenis bahan olah karetnya dapat dikelompokan menjadi lateks pekat, karet bongkah dan karet spesifik teknis atau karet remah (crumb rubber).

Sebagian besar produk karet Indonesia diolah menjadi karet remah (crumb rubber) dan dibedakan dengan pemberian kode yaitu Standard Indonesian Rubber (SIR). Bahan olah karet yang lain dijadikan dalam bentuk Ribbed Smoked Sheets (RSS) dan lateks pekat. Penurunan mutu bahan jadi karet disebabkan proses prakoagulasi (Oktavia et al, 2014; Fatkhurrahman \& Sari, 2016). Prakoagulasi akan menjadi masalah dalam proses pengolahan karet konvensional jenis RSS dan krepe (crepe) sedangkan dalam proses pengolahan karet remah tidak menjadi masalah. Prakoagulasi pada lateks dipengaruhi oleh beberapa faktor, diantaranya terjadinya aktivitas mikroorganisme, enzim, iklim, pengangkutan, dan kontaminasi kotoran dari luar. Upaya pencegahan terjadinya prakoagulasi perlu memperhatikan faktor berikut yaitu alat pemanen dan pengangkutan harus bersih dan tahan karat, lateks harus segera diangkut ke tempat pengolahan tanpa banyak goncangan, lateks tidak boleh terkena sinar matahari langsung, dan dapat menggunakan zat anti koagulan seperti amonia $\left(\mathrm{NH}_{3}\right)$ atau natrium sulfit $\left(\mathrm{Na}_{2} \mathrm{SO}_{3}\right)$.

Karet sit asap yang dikenal dengan Ribbed Smoked Sheet (RSS) diproduksi dari karet sit basah yang dikeringkan menggunakan asap dari pembakaran kayu, umumnya kayu dari batang pohon karet (Vachlepi \& Wijaya, 2015). Permasalahan yang ada dalam proses pengasapan dan pengeringan karet RSS yaitu konsentrasi asap ruangan tidak stabil, suhu pengasapan optimum tidak konstan, dapat menimbulkan kebakaran dan waktu pengasapan yang lama (3-6 hari). Pengasapan selama ini dikendalikan secara konvensional sehingga sulit menjaga proses pengeringan karet sit. Akibat yang ditimbulkan dari pengasapan yang tidak sempurna yaitu menyebabkan warna RSS tidak seragam, karet teroksidasi (rapuh/lengket), banyak gelembung udara, dan banyak jamur dipermukaannya sehingga hasil kering tidak masuk dalam tingkatan mutu karet RSS tetapi sebagai pencampur karet remah SIR 20 dengan nilai lebih rendah. Proses pengeringan RSS memerlukan kayu sebanyak $4 \mathrm{~m}^{3}$ per ton karet kering dengan waktu 5-6 hari. Disamping itu, harga kayu karet yang semakin mahal dan sulit mendapatkannya.

Penelitian ini bertujuan merancang bangun sistem kendali otomatis yang dapat berfungsi untuk mengatur suhu asap kayu karet agar tetap terjaga konstan dan mengukur konsumsi bahan bakar kayu dalam proses pengeringan karet sit basah menjadi RSS di kamar asap. Dengan demikian diharapkan dapat menghasilkan produk RSS berkualitas unggul (RRS 1) yang dominan dibandingkan tingkat mutu RSS yang lain.

\section{BAHAN DAN METODE}

Penelitian ini dilaksanakan pada bulan Maret-Desember 2015. Penelitian dilakukan dengan mencangkup beberapa lokasi antara lain Laboratorium Balai Penelitian Sungei Putih, Laboratorium Instrumentasi dan Elektronika Fateta IPB, dan Laboratorium Balai Besar Pengembangan Mekanisasi Pertanian.

Bahan yang digunakan pada penelitian ini adalah karet sit basah dan kayu bakar dengan kadar air yang berbeda. Sampel karet sit basah diperoleh dari Pabrik Kebun Sarang Giting, PT. Perkebunan Nusantara III, Sumatera Utara. Adapun bahan bakar kayu karet sebagai sumber asap diperoleh dari petani karet rakyat di Kabupaten Deli Serdang, Sumatera Utara. Peralatan untuk aplikasi sistem kendali meliputi Laptop atau PC, Arduino Mega 2560, Mikro AVR Atmega 8535, Sensor LM 35, Sensor Asap MQ-135, LCD 16x2, dan Kipas AC (Alternating Current). Sedangkan peralatan untuk pengambilan data meliputi Termokopel, Timbangan, dan Drying Oven. Rangkaian alat kendali suhu pada ruang asap RSS disajikan pada Gambar 1 sebagai berikut.

Tahapan dalam pelaksanaan kegiatan penelitian sebagaimana disajikan dalam Gambar 2. Kegiatan penelitian diawali dengan merancang bangun ruang pengasapan (kamar asap). Ketika telah diperoleh ruang pengasapan, kegiatan 


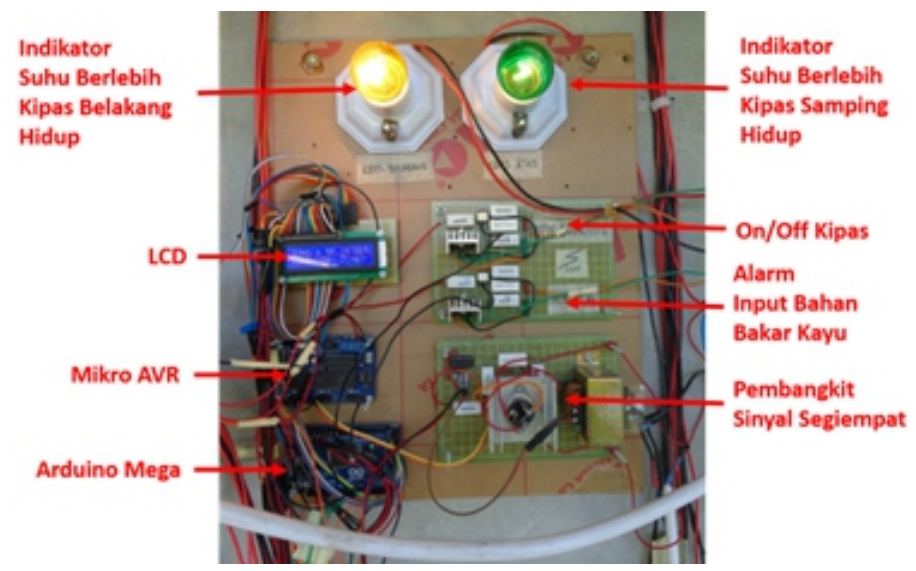

Gambar 1. Rangkaian kendali suhu ruang asap RSS Figure 1. Circuit to controlling temperature in chamber

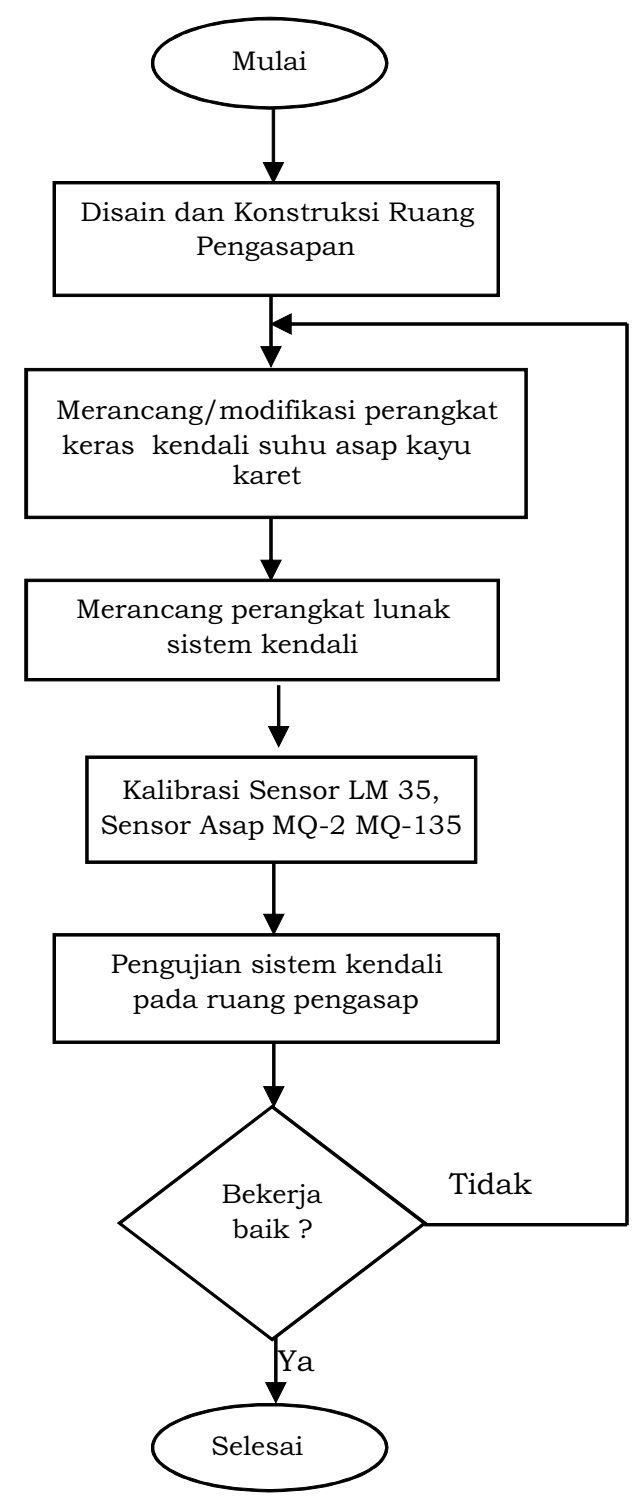

Gambar 2. Diagram alir sistem kendali ruang pengasapan RSS Figure 2. Flowcart of design temperature control for RSS 
penelitian dilanjutkan dengan merancang dan memodifikasi perangkat keras untuk kendali suhu asap kayu karet. Setelah perangkat keras untuk sistem kendali terbentuk, maka diteruskan dengan mempersiapkan perangkat lunak sistem kendali ruang pengasapan. Untuk menjamin hasil pengukuran, maka dilakukan kalibrasi terhadap Sensor LM 35 dan Sensor Asap MQ-2 serta MQ-135. Tahap terakhir dalam rangkaian kegiatan penelitian adalah uji coba sistem kendali pada ruang pengasapan (kamar asap) karet sit asap. Selama pengujian dilakukan pengukuran sebagai berikut :

1. Berat awal RSS basah $(\mathrm{Kg})$

2. Berat RSS setelah 12 jam, 24 jam, 36 jam, 48 jam dan 60 jam (Kg)

3. Panjang awal RSS(cm)

4. Panjang akhir RSS (cm)

5. Lebar awal RSS (cm)

6. Lebar akhir RSS $(\mathrm{cm})$

7. Tebal awal RSS (mm)

8. Tebal akhir RSS (mm)

9. Diameter kayu asap $(\mathrm{cm})$

10. Kadar air kayu asap (\%)

\section{HASIL DAN PEMBAHASAN}

Ruang penelitian pengasapan karet RSS dibangun dengan ukuran panjang $5 \mathrm{~m}$, lebar $3 \mathrm{~m}$ dan tinggi $4 \mathrm{~m}$. Dinding berupa batu bata merah yang diplaster hanya sisi luar bangunan. Susunan atap ruang asap dari bawah ke atas yaitu papan kayu, asbes dan seng. Pembangunan sistem pengendalian ruang pengasapan karet berupa perangkat keras dan perangkat lunak. Dalam ruang asap tersusun atas 3 rak bertingkat dengan jarak $130 \mathrm{~cm}$. Adapun bagian perangkat keras yaitu Mikrokontroller Arduino Mega 2560, Mikrokontroller DT-AVR, 1 buah rangkai zero crossing, 2 buah rangkaian pengedali on/off, 1 buah trafo $3 \mathrm{~A}, 1$ buah trafo $1 \mathrm{~A}, 3$ lampu indikator, 6 sensor suhu dan 1 sensor asap. Fungsi mikrokontroller yaitu melakukan penerimaan dan pengolahan data analog serta mengirimkan data digital untuk menggerakkan perangkat keras. Gambar 3 menunjukkan pengujian pengasapan karet sit basah menjadi RSS dengan pengendali temperatur asap yang berasal dari input bahan bakar kayu karet.

Hasil pengujian sistem kendali suhu asap kayu karet adalah proses pengasapan karet RSS terbagi pada 4 tingkatan suhu yaitu suhu $40^{\circ} \mathrm{C}-45^{\circ} \mathrm{C}$ selama 12 jam (Gambar 4), suhu $45^{\circ} \mathrm{C}-50^{\circ} \mathrm{C}$ selama 12 jam (Gambar 5), suhu $50^{\circ} \mathrm{C}-55^{\circ} \mathrm{C}$ selama 12 jam (Gambar 6), dan suhu $55^{\circ} \mathrm{C}-60^{\circ} \mathrm{C}$ selama 24 jam (Gambar 7). Keberhasilan pengujian ini dicapai selama 60 jam atau 2,5 hari. Adapun proses pengasapan RSS secara konvensional membutuhkan waktu lebih lama yaitu 5-6

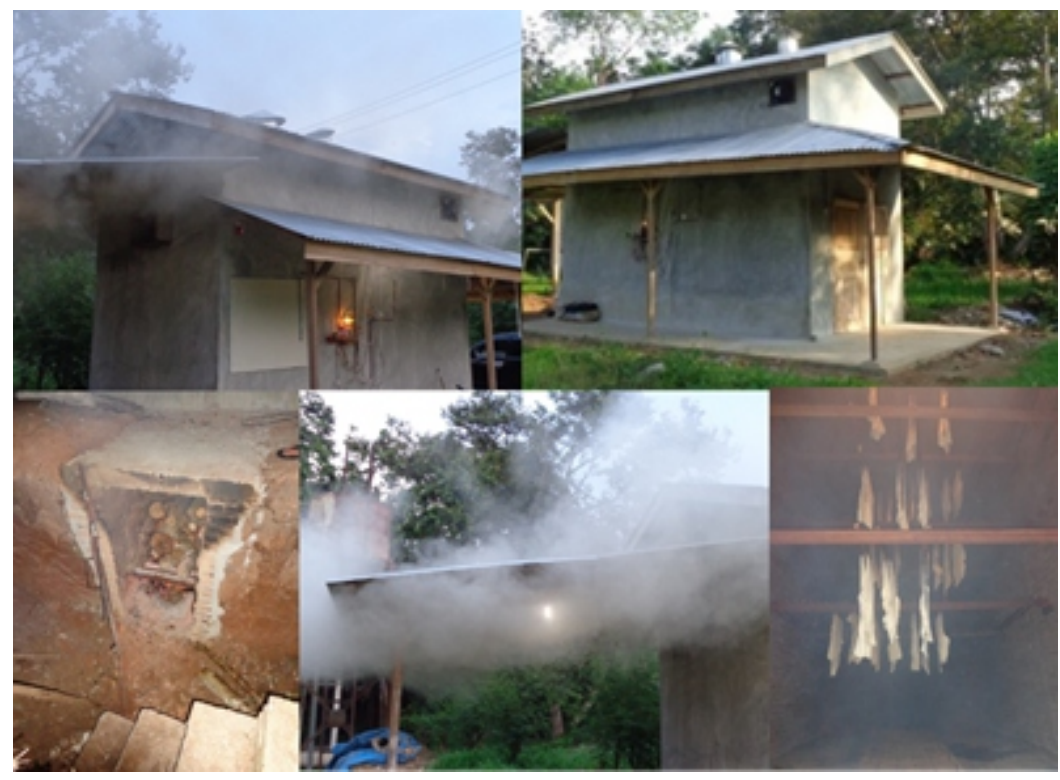

Gambar 3. Pengujian ruang kendali temperatur asap RSS Figure 3. Experiment smoke temperature control for RSS 

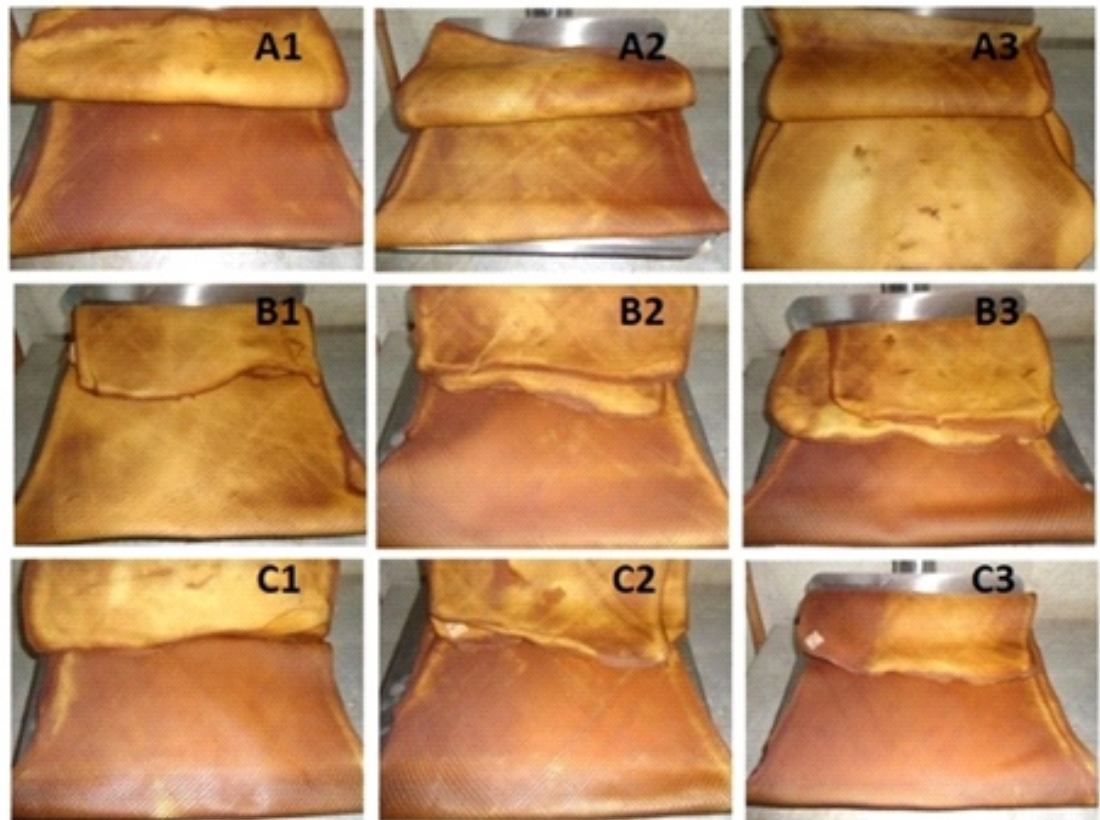

Keterangan (Remaks):

$\mathrm{A} 1, \mathrm{~A} 2, \mathrm{~A} 3$ = rak atas; $\mathrm{B} 1, \mathrm{~B} 2, \mathrm{~B} 3=$ rak tengah; $\mathrm{C} 1, \mathrm{C} 2, \mathrm{C} 3=$ rak bawah

Gambar 4. RSS pengasapan 12 Jam

Figure 4. Smoking RSS for 12 hours
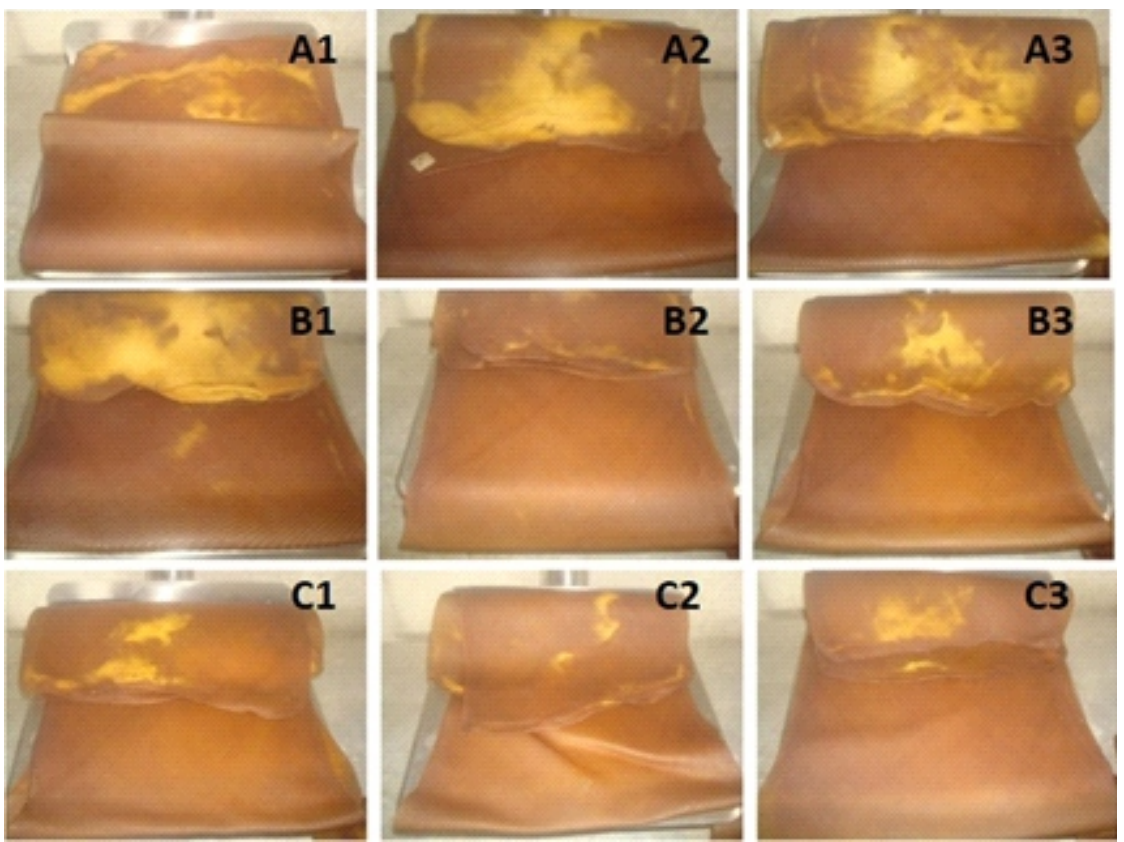

Keterangan (Remaks):

$\mathrm{A} 1, \mathrm{~A} 2, \mathrm{~A} 3$ = rak atas; $\mathrm{B} 1, \mathrm{~B} 2, \mathrm{~B} 3=$ rak tengah; $\mathrm{C} 1, \mathrm{C} 2, \mathrm{C} 3=$ rak bawah

Gambar 5. RSS pengasapan 24 Jam

Figure 5. Smoking RSS for 24 hours 

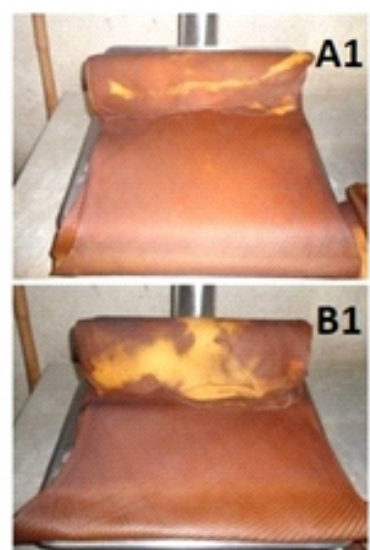

B1
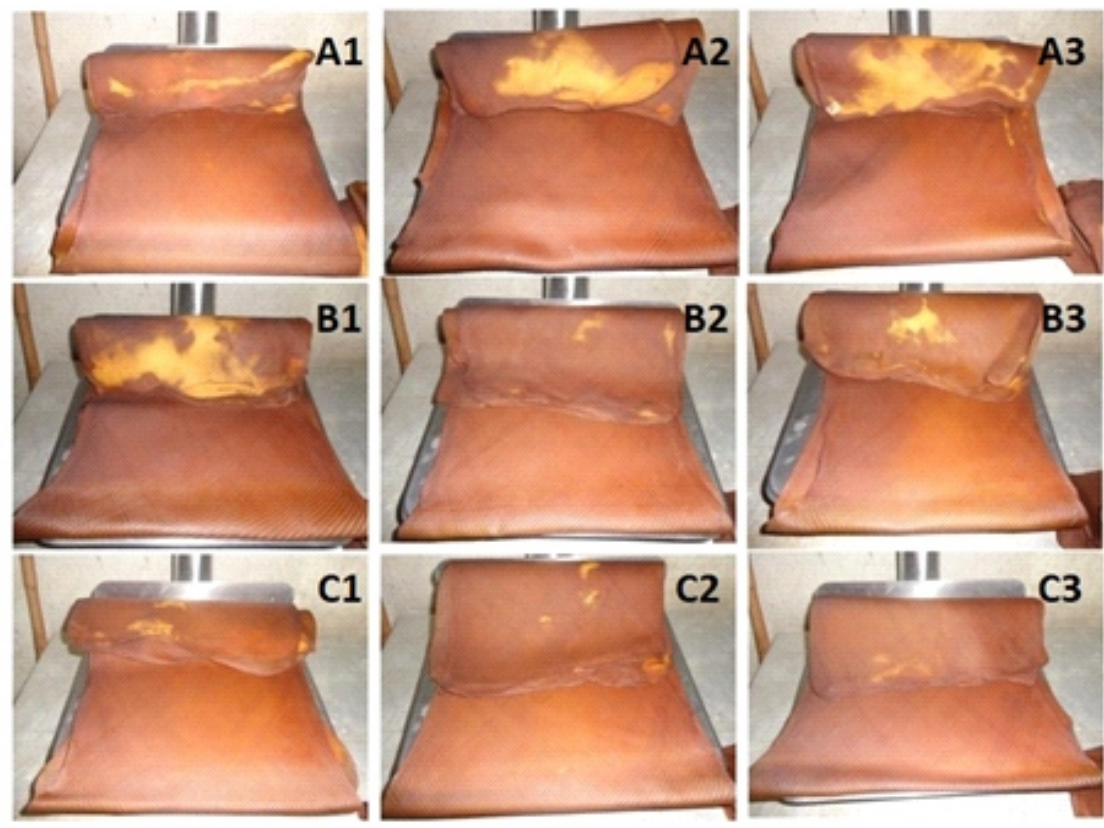

Keterangan (Remaks):

$\mathrm{A} 1, \mathrm{~A} 2, \mathrm{~A} 3$ = rak atas; B1, B2, B3 = rak tengah; $\mathrm{C} 1, \mathrm{C} 2, \mathrm{C} 3=$ rak bawah

Gambar 6. RSS pengasapan 36 Jam

Figure 6. Smoking RSS for 36 hours

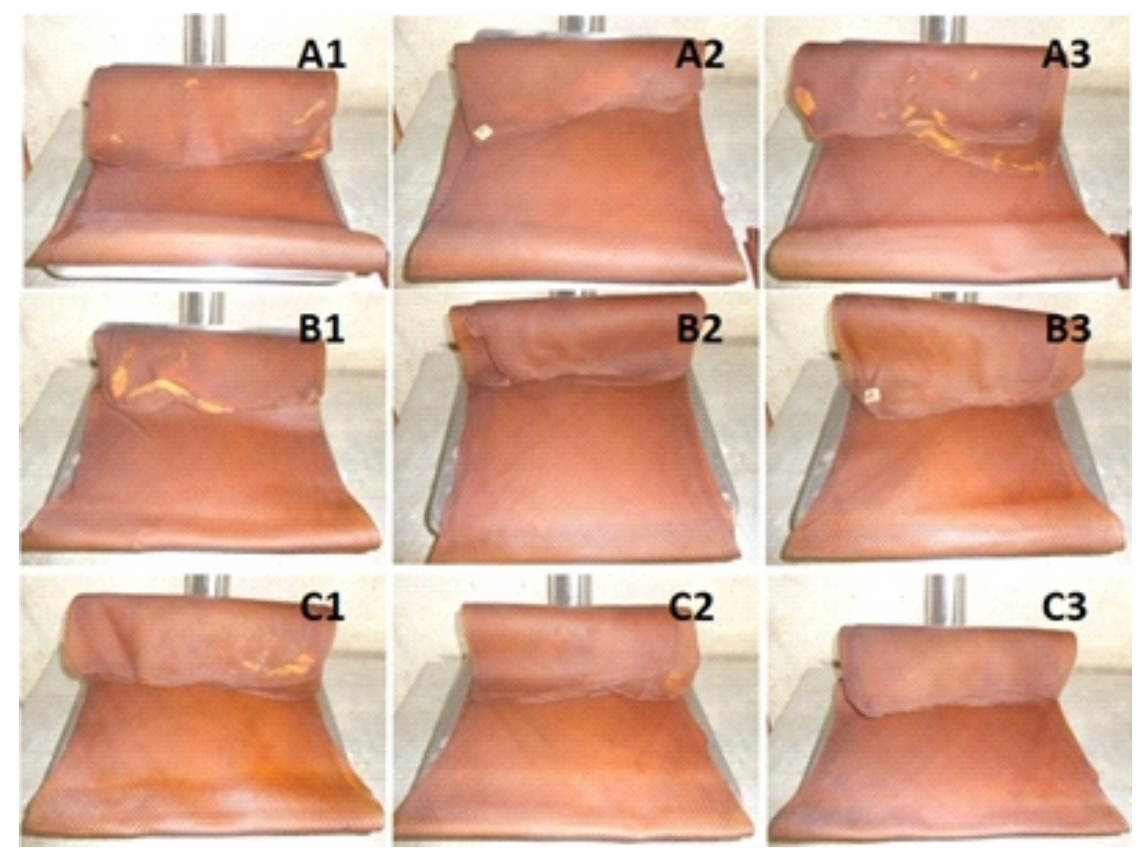

Keterangan (Remaks):

$\mathrm{A} 1, \mathrm{~A} 2, \mathrm{~A} 3$ = rak atas; $\mathrm{B} 1, \mathrm{~B} 2, \mathrm{~B} 3$ = rak tengah; $\mathrm{C} 1, \mathrm{C} 2, \mathrm{C} 3=$ rak bawah

Gambar 7. RSS pengasapan 48 Jam

Figure 7. Smoking RSS for 48 hours 
hari. Hari pertama, pengasapan dilakukan dengan suhu kamar asap $40^{\circ}-45^{\circ} \mathrm{C}$. Pada tingkat pertama air yang terdapat pada permukaan lembaran sit dapat diuapkan. Pertukaran udara dan uap air melalui ventilasi sedikit terbuka. Pada tingkat pengasapan pertama ini, difusi air dari dalam lembaran tidak merupakan faktor pembatas, sehingga bagian asap dengan mudah dapat diserap oleh permukaan sit, dan sit ini akan berubah warna dari putih menjadi cokelat. Hari kedua, suhu pengasapan kamar asap dinaikkan menjadi $45^{\circ}-50^{\circ} \mathrm{C}$. Air yang melekat pada permukaan mulai menguap. Pada fase ini, ventilasi ruangan sedikit dibuka agar uap air dari ruangan mudah keluar. Hari ketiga, suhu pengasapan kamar asap dinaikkan menjadi $50^{\circ}-55^{\circ} \mathrm{C}$. Dan sit yang terbentuk sudah berwarna coklat. Hari keempat, pengasapan dilakukan dengan suhu kamar asap $55^{\circ}-$ $60^{\circ} \mathrm{C}$. Hari kelima, pengasapan dilakukan dengan mempertahankan suhu kamar asap $60^{\circ} \mathrm{C}$. Hal ini memperlihatkan bahwa waktu yang diperlukan menjadi RSS dengan mutu I lebih cepat sehingga akan mengurangi konsumsi bahan bakar kayu asap dan meningkatkan premi kerja.

Berdasarkan penilaian mutu karet RSS yang dihasilkan dari pengujian sistem kendali terlihat bahwa RSS berwarna cokelat transparan, tidak timbul gelembung dan lembaran tidak tambah panjang atau putus.
Karet RSS menjadi dominan mutu RSS 1 yang merupakan mutu RSS tertinggi setelah terjadi penguapan air sebesar 35,19\% (Nurhidayati, hakim, \& Asmara, 2015). Dimensi panjang karet RSS pengujian berubah pada panjangnya akan menjadi menyusut 4,93\% dan lebarnya menyusut menjadi $8,33 \%$ serta ketebalan bertambah $5,16 \%$ (Tabel 1).

Kegiatan penelitian terbukti dapat meningkatkan kualitas karet RSS dengan komposisi RRS I mendominasi dan memperkecil persentase mutu cutting serta mempercepat proses pengasapan menjadi 60 jam atau hanya selama 2,5 hari. Kemajuan teknologi sistem kendali dapat diterapkan pada tingkat kelompok tani karet, perkebunan negara maupun perkebunan swasta. Dengan kondisi harga karet yang rendah saat ini maka perlu dilakukan upaya peningkatan kualitas dan efisiensi dalam produksi RSS. Mutu RSS I mempunyai harga lebih tinggi dan dapat disimpan dalam waktu lama. Dengan penerapan sistem kendali suhu asap kayu karet dan mengatur input bakar kayu berbasis mikrokontroller untuk pengasapan karet RSS (Ribbed Smoked Sheets) maka akan meningkatkan kapasitas produksi 2 kali lipat dalam rentang waktu yang sama, mengefisiensikan konsumsi bahan bakar kayu asap dan memaksimalkan karet RSS mutu I. Konsumsi bahan bakar dengan

Tabel 1. Perubahan berat dan ukuran RSS

Table 1. Alteration of RSS weight and size

\begin{tabular}{|c|c|c|c|c|c|c|c|c|c|c|c|c|}
\hline \multirow{3}{*}{$\begin{array}{c}\text { Nomor } \\
\text { ulangan } \\
\text { Repetition }\end{array}$} & \multicolumn{3}{|c|}{$\begin{array}{l}\text { Bobot } \\
\text { Weight }\end{array}$} & \multicolumn{3}{|c|}{$\begin{array}{c}\text { Panjang } \\
\text { Lenght }\end{array}$} & \multicolumn{3}{|c|}{$\begin{array}{l}\text { Lebar } \\
\text { Widht }\end{array}$} & \multicolumn{3}{|c|}{$\begin{array}{c}\text { Tebal } \\
\text { Thickness }\end{array}$} \\
\hline & Awal & Akhir & & Awal & Akhir & & Awal & Akhir & & Awal & Akhir & \\
\hline & $\begin{array}{l}\text { Initial } \\
(\mathrm{Kg})\end{array}$ & $\begin{array}{l}\text { Final } \\
(\mathrm{Kg})\end{array}$ & $\%$ & $\begin{array}{l}\text { Initial } \\
(\mathrm{cm})\end{array}$ & $\begin{array}{l}\text { Final } \\
\text { (cm) }\end{array}$ & $\%$ & $\begin{array}{l}\text { Initial } \\
(\mathrm{cm})\end{array}$ & $\begin{array}{l}\text { Final } \\
(\mathrm{cm})\end{array}$ & $\%$ & $\begin{array}{l}\text { Initial } \\
(\mathrm{mm})\end{array}$ & $\begin{array}{l}\text { Final } \\
(\mathrm{mm})\end{array}$ & $\%$ \\
\hline 1 & 1,63 & 1,05 & 35,70 & 122,17 & 177,50 & 3,82 & 43,72 & 39,78 & 9,01 & 3,23 & 3,37 & 4,33 \\
\hline 2 & 1,66 & 1,06 & 36,14 & 120,78 & 113,00 & 6,44 & 43,67 & 40,78 & 6,62 & 3,10 & 3,10 & 0 \\
\hline 3 & 1,83 & 1,21 & 33,88 & 113,44 & 108,33 & 4,50 & 49,28 & 44,72 & 9,25 & 2,97 & 3,31 & 11,45 \\
\hline Rata-rata & 1,71 & 1,11 & 35,19 & 118,80 & 112,94 & 4,93 & 45,56 & 41,76 & 8,33 & 3,10 & 3,26 & 5,16 \\
\hline
\end{tabular}

Tabel 2. Hasil pengujian RSS dengan kendali temperatur asap

Table 2. Result test of smoke temperature control

\begin{tabular}{ccccccc}
\hline \multirow{2}{*}{$\begin{array}{c}\text { Nomor } \\
\text { ulangan }\end{array}$} & \multicolumn{5}{c}{ Bobot pada setiap tingkatan mutu karet sit asap } \\
\cline { 2 - 7 } Repetition & $\begin{array}{c}\text { RSS I } \\
(\mathrm{Kg})\end{array}$ & $\begin{array}{c}\text { RSS II } \\
(\mathrm{Kg})\end{array}$ & $\begin{array}{c}\text { RSS III } \\
(\mathrm{Kg})\end{array}$ & $\begin{array}{c}\text { Cutting } \\
(\mathrm{Kg})\end{array}$ & $\begin{array}{c}\text { RSS I } \\
(\%)\end{array}$ & $\begin{array}{c}\text { Cutting } \\
(\%)\end{array}$ \\
\hline 1 & 32.70 & 0.00 & 0.00 & 0.30 & 99.09 & 0.91 \\
2 & 34.60 & 0.00 & 0.00 & 0.30 & 99.14 & 0.86 \\
3 & 34.90 & 0.00 & 0.00 & 0.50 & 98.59 & 1.41 \\
\hline Rata-Rata & 34.1 & 0.00 & 0.00 & 0.37 & 98.94 & 1.06 \\
\hline
\end{tabular}




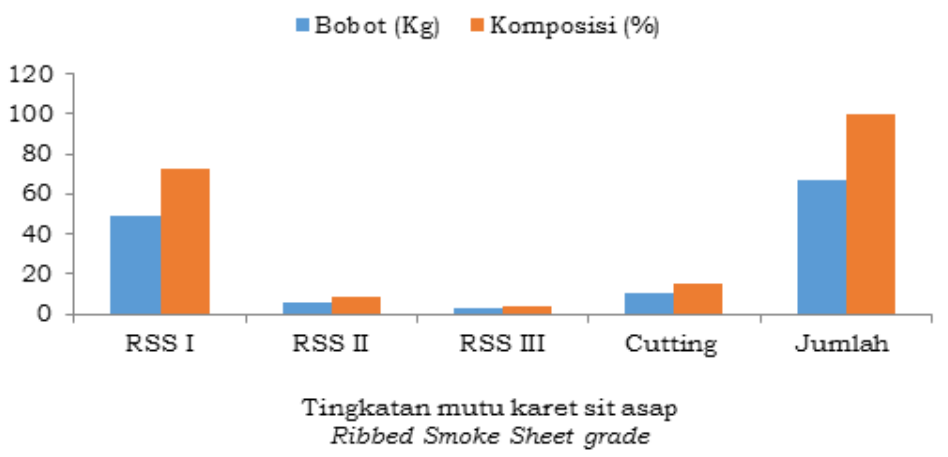

Gambar 8. Produksi RSS salah satu Perkebunan di Jawa Barat tanggal 27 April 2013 Figure 8. RSS production in West Java plantation at 27 April 2013

Tabel 3. Produksi RSS salah satu perkebunan di Jawa Tengah tahun 2013 Table 3. Annual RSS production in Central Java plantation at 2013

\begin{tabular}{|c|c|c|c|c|c|c|c|c|c|c|c|c|c|}
\hline \multirow{2}{*}{$\begin{array}{l}\text { Mutu RSS } \\
\text { RSS grade }\end{array}$} & \multicolumn{13}{|c|}{$\begin{array}{c}\text { Bulan, } 2013 \text { (dalam Kg) } \\
\text { Month, } 2013(\text { in } \mathrm{Kg} \text { ) }\end{array}$} \\
\hline & Januari & Februari & Maret & April & Mei & Juni & Juli & Agustus & September & Oktober & November & Desember & $\begin{array}{c}\text { Jumlah } \\
\text { Total }\end{array}$ \\
\hline RSS 1 & 56492 & 75173 & 104569 & 97591 & 102742 & 88634 & 103668 & 61747 & 48842 & 30205 & 36310 & 58364 & 864337 \\
\hline RSS 2 & & & & & & & & & & & & & 0 \\
\hline RSS 3 & & 226 & & & & & & & & & & & 226 \\
\hline RSS 4 & 647 & 22564 & 4331 & 14692 & 6369 & 5979 & 10924 & 1647 & 3459 & 4307 & 11582 & 16103 & 102604 \\
\hline Cutting & 491 & 1703 & 1162 & 1960 & 1516 & 872 & 894 & 451 & 696 & 518 & 811 & 1130 & 12204 \\
\hline Jumlah & 57630 & 99666 & 110062 & 114243 & 110627 & 95485 & 115486 & 63845 & 52997 & 35030 & 48703 & 75597 & 979371 \\
\hline \multirow{2}{*}{$\begin{array}{l}\text { Mutu RSS } \\
\text { RSS grade }\end{array}$} & \multicolumn{13}{|c|}{$\begin{array}{l}\text { Bulan, } 2013 \text { (dalam \%) } \\
\text { Month, } 2013 \text { (in \%) }\end{array}$} \\
\hline & Januari & Februari & Maret & April & Mei & Juni & Juli & Agustus & September & Oktober & November & Desember & $\begin{array}{l}\text { Rata-rata } \\
\text { Average }\end{array}$ \\
\hline RSS 1 & 98,03 & 75,42 & 95,01 & 85,42 & 92,87 & 92,83 & 89,77 & 96,71 & 92,16 & 86,23 & 74,55 & 77,20 & 88,02 \\
\hline RSS 2 & - & - & - & - & - & - & - & - & - & - & - & - & - \\
\hline RSS 3 & - & 0,23 & - & - & - & - & - & - & - & - & - & - & 0,02 \\
\hline RSS 4 & 1,12 & 22,64 & 3,94 & 12,86 & 5,76 & 6,26 & 9,46 & 2,58 & 6,53 & 12,30 & 23,78 & 21,30 & 10,71 \\
\hline Cutting & 0,85 & 1,71 & 1,06 & 1,72 & 1,37 & 0,91 & 0,77 & 0,71 & 1,31 & 1,48 & 1,67 & 1,49 & 1,25 \\
\hline Jumlah & 100 & 100 & 100 & 100 & 100 & 100 & 100 & 100 & 100 & 100 & 100 & 100 & 100 \\
\hline
\end{tabular}

sistem kendali suhu asap masuk diperlukan kayu karet sebanyak $1,18 \mathrm{~m}^{3}$ dengan kadar air kayu karet 31,23\%. Adapun kapasitas tampung ruang pengujian pengasapan karet RSS sebanyak $1.000 \mathrm{Kg}$.

Hasil pengujian ruang kendali panas asap adalah RSS mutu I sebanyak 98,59\% dan karet cutting sebanyak 1,06\% (Tabel 2). RSS I yang dihasilkan dari hasil penelitian jauh lebih tinggi daripada RSS I yang di produksi secara konvensional di salah satu perkebunan di Jawa Barat dan Jawa Tengah (Gambar 8 dan Tabel 3). Kelebihan sistem kendali ini yaitu adanya sistem sirkulasi udara panas paksa terkontrol sehingga waktu yang dibutuhkan lebih singkat.

\section{KESIMPULAN}

Kesimpulan yang dapat ditarik berdasarkan hasil penelitian yang telah diperoleh yaitu bahwa disain dan pengujian pengendalian temperatur asap kayu karet berbasis mikrokontroller untuk pengasapan karet sit basah menjadi RSS (Ribbed Smoked Sheets) menggunakan mikrokontroller menghasilkan RSS mutu I (RSS 1) sebanyak 98,94\% dengan waktu yang dibutuhkan untuk pengasapan selama 60 jam dan input bahan bakar kayu sebanyak 1, $18 \mathrm{~m}^{3}$. Tingkat kecerahan warna RSS dapat diatur dengan memisahkan jalur udara panas dan jalur asap. Selanjutnya pemberian konsentrasi asap dapat diatur menggunakan sistem buka-tutup pintu asap dengan skala konsentrasi dan waktu tertentu.

\section{UCAPAN TERIMA KASIH}

Penulis mengucapkan terima kasih kepada Badan Penelitian dan Pengembangan Pertanian yang telah membiayai riset dengan Program SMARD melalui Kerjasama Penelitian dan Pengembangan Pertanian (KKP3N). Penulis juga mengucapkan terima kasih kepada 
Kepala Balai Penelitian Sungei Putih - Pusat Penelitian Karet, Dekan Fakultas Teknologi Pertanian IPB, Kepala Balai Besar Pengembangan Mekanisasi Pertanian, Dekan Fakultas Teknik Universitas Negeri Medan atas ijin penelitian kerjasama yang diberikan.

\section{DAFTAR PUSTAKA}

Cifriadi, A., Chalid, M., \& Puspitasari, S. (2017). Characterization of hydrogenated natural rubber synthesized by diimide transfer hydrogenation. International Journal of Technology, 3, 448-457. Doi: 10.14716/ijtech.v8i3.1991

Direktorat Jenderal Perkebunan. (2016). Statistik perkebunan Indonesia 20152017 : Karet. Jakarta, Indonesia: Ditjenbun, Kementerian Pertanian.

Fatkhurrahman, J.A., \& Sari, I.R.J. (2016). Pengaruh waktu terhadap kestabilan intensitas berkas cahaya pada lateks. Prosiding Seminar Nasional Kulit, Karet dan Plastik ke-5 (p. 225-232). Yogyakarta, Indonesia: Balai Besar Kulit, Karet, Plastik.

Ginting, R., Siregar, I., \& Ginting, T.U.H.S. (2015). Perancangan alat penyadap karet di Kabupaten Langkat Sumatera Utara dengan Metode Quality Function deployment (QFD) dan Model Kano. Jati Undip, X(1), 33-40.
Hendratno, S. (2015). Analis is perkembangan pasar karet remah SIR. Warta Perkaretan, 34(2), 161-176.

Kementerian Pertanian. (2015). Outlook karet komoditas pertanian subsektor perkebunan. Jakarta, Indonesia: Pusat data dan Sistem Informasi Pertanian, Kementerian Pertanian.

Munafidza., Supardi, S., \& Nurjayanti, E.D. (2015). Analisis profitabilitas tanaman karet (Hevea brasiliensis) pada PT. Perkebunan Nusantara IX (Persero) Kebun Balong/Beji/Kalitelo Kabupaten Jepara. Mediagro, 11(2), 34-45.

Nurhidayati, I., Hakim, D.B., \& Asmara, A. (2015). Integrasi pasar karet alam sit asap antara produsen utama dengan pasar berjangka dunia. Jurnal Manajemen \& Agribisnis, 12(3), 204215. Doi : 10.17358/JMA.12.3.204

Oktavia, V., Suroso, E., \& Utomo, T.P. (2014). Strategi optimalisasi bahan baku lateks pada industri karet jenis ribbed smoked sheet (RSS). Jurnal Teknologi Industri dan Hasil Pertanian, 19(2), 179-193.

Vachlepi, A., \& Wijaya, T. (2013). Perkembangan karet alam di Myanmar. Warta Perkaretan, 32(1), 3845. 